\title{
A construção histórica do consumo feminino e das estruturações discursivas da autoridade em "Escolhendo e comprando com Helena Brazill" (Diário de Notícias, 1962-1963)
}

\section{Eliza Bachega Casadei}

\section{Introdução}

operação que efetua a partilha entre o discurso do especialista e o discurso
do leigo, para Certeau (2008), nunca é aleatória: ela é antes de tudo, um
exercício que engendra um dever fazer a um dever crer a partir de codificações associadas tanto às práticas sociais de um determinado grupo quanto às suas formas imaginárias de legitimação do discurso, que se materializam em operações narrativas, retóricas e textuais específicas. É nesse sentido que Maingueneau (2002) irá colocar que dos especialistas espera-se não somente um conhecimento consistente das bases teóricas e práticas de seus campos de atuação, mas antes de tudo, uma alta especialização das competências linguísticas necessárias para o ingresso no campo, de forma que as maneiras de escrita não se constituem como meros canais de emissão do conhecimento a outros, mas sim, como fiadoras da suposta veracidade de um relato. O discurso de um especialista, portanto, nunca se constrói no vazio: a filiação a uma determinada comunidade linguística é um elemento abonador importante não apenas da confiabilidade do relato, mas também da credibilidade daquele que o conta, posto que as formas do narrar são elementos componentes não apenas do ethos, mas da própria legitimidade dos lugares de fala e daqueles que os ocupam.

Isso posto, contudo, há mais um elemento em jogo: as formas de escrita que comportam os discursos dos especialistas mudam ao longo do tempo, de maneira que as estratégias retóricas e narrativas utilizadas pelos diferentes grupos de experts para manter a sua credibilidade no discurso são historicamente marcadas. É a partir 
dessa perspectiva que o presente artigo tem como objetivo mapear as estratégias discursivas de construção de um lugar de autoridade para o discurso do especialista a partir de um objeto específico: a coluna "Escolhendo e Comprando com Helena Brazil”, publicada de 1962 a 1963, no jornal Diário de Notícias (DN). Ao nomear-se como "conselheira de compras" para mulheres, Brazil colocava-se como uma expert no assunto e, com isso, utilizava-se de uma série de estratégias discursivas recorrentes para a construção de um lugar de autoridade no texto - estratégias essas que deixam entrever uma triangulação discursiva bastante específica e historicamente demarcada entre o lugar do narrador (como lugar do especialista), o lugar do leitor e o imaginário sobre o consumo. Uma das figuras emblemáticas do gênero editorial da educação financeira para mulheres, a coluna misturava anúncios comerciais com aconselhamentos financeiros, dicas de comportamento e reclamações sobre o governo, em um espaço em que as fronteiras entre jornalismo e publicidade não estavam demarcadas de forma precisa. Dentre suas principais características discursivas, destaca-se o profundo tom testemunhal que marcava os relatos, o que funcionava como um lastro de veracidade dos conselhos apresentados e colocava-os na esfera de uma experiência adquirida com os anos.

A partir do mapeamento dessas estratégias discursivas de construção do lugar de autoridade no texto, procuraremos entender de forma mais apurada alguns dos alicerces da relação entre comunicação e consumo nos anos 1960 no Brasil em suas hibridizações com a linguagem jornalística do período. Mais do que isso, adotaremos como foco especialmente os elementos que se referem à construção discursiva do corpo feminino como um corpo que consome, em um texto que se constrói como "a voz do especialista" sobre o tema.

Os estudos sobre o gênero são relevantes para um entendimento mais pormenorizado das relações entre comunicação e consumo, para Stillerman (2015: 109), por duas razões. A primeira delas é a de que uma abordagem voltada exclusivamente para a categoria das classes sociais não é suficiente para abarcar os eixos de desigualdade que diferenciam os consumidores, de forma que é necessário entender os mecanismos a partir dos quais homens e mulheres se relacionam com o consumo de maneiras diferentes. A segunda, correlacionada à primeira, refere-se à necessidade de estudos que abarquem as formas como os corpos femininos e masculinos foram construídos simbolicamente como corpos que consomem de formas diferentes ao longo da história - mecanismos estes implicados nas maneiras como a feminilidade e a masculinidade foram simbolicamente postas em visibilidade, bem como as mudanças que essas representações dos corpos que consomem sofreram ao longo do tempo.

A coluna de Helena Brazil no Diário de Notícias (DN) marca uma dessas emergências históricas da construção discursiva do corpo feminino como corpo consumidor a partir de um jogo que construía o lugar de autoridade do narrador a partir de estratégias narrativas que efetuavam um espelhamento entre o testemunho do 
especialista e o corpo da consumidora, com o engendramento de uma suposta relação mimética entre um e outro, conforme detalharemos a seguir. No caso da coluna de Helena Brazil, a construção de um lugar de autoridade no discurso passa por uma questão da mediação do lugar imaginário do gênero e do consumo, de forma que eles são ingredientes importantes para uma suposta conquista de um lugar de fala.

Para isso, esmiuçaremos, em um primeiro momento, o contexto em que a coluna de Helena Brazil estava inserida, tanto em termos do projeto editorial do jornal que a abrigava quanto dos imaginários sobre o consumo feminino presentes na época. Em seguida, faremos o estudo das estratégias discursivas de construção do lugar de autoridade no discurso em sua coluna, bem como de suas relações com a construção do corpo feminino como actante consumidor. Para isso, iremos decompor os seus textos no nível formal (especialmente no que se refere aos planos narrativo e retórico) e no plano do conteúdo, para entendermos as estratégias de construção desse lugar de autoridade no relato.

\section{Contexto histórico: imaginários do consumo feminino e o projeto editorial do Diário de Notícias}

As práticas de consumo sempre foram atravessadas pelas questões de gênero. Conforme posto por Stillerman (2015: 111), desde o século XIX, as práticas triviais de consumo eram muito mais associadas às mulheres do que aos homens, uma vez que a elas cabiam os cuidados domésticos e com a esfera do lar, ao passo que as atividades públicas, o trabalho e a liderança eram representadas como esferas masculinizadas. O consumo vulgar, feito para o mantimento da casa, era considerado uma atividade menos prestigiada e, por isso, pensada como uma atividade tipicamente feminina. Assim, muito embora as mulheres fossem dependentes financeiramente de seus maridos (e fossem proibidas de uma gama de atividades financeiras como possuir uma conta bancária), elas ainda eram consideradas os principais actantes do mundo do consumo. "As mulheres de classe média compravam usando o crédito de seus maridos, e os comerciantes as encorajavam a gastar somas consideráveis, sabendo que seus maridos seriam obrigados a pagar a conta”. E, assim, estabelecia-se uma triangulação a partir da qual "os comerciantes se aliavam às mulheres contra os seus maridos". (Stillerman, 2015: 112). Os espaços de comércio eram um dos poucos lugares públicos que permitiam uma circulação mais livre de senhoras.

Embora o protagonismo feminino no mundo do consumo continue ao longo do século XX, tal regência passa a ser urdida a partir de configurações diversas. Durante as primeiras décadas, as mulheres passam a ser representadas de uma maneira mais consistente como "especialistas em consumo", principalmente a partir da ótica de um cuidado com a família e, especialmente, com as crianças. Apelava-se ao senso de responsabilidade das mulheres com a saúde de seus filhos e o bem-estar do marido 
como uma estratégia central de marketing. Tratava-se de um consumo voltado para o outro, tanto no que se refere à satisfação de necessidades familiares quanto para a efetivação de hábitos sobre o que se esperava de uma mulher na época (tais como uma boa manutenção da casa e da higiene da família). Tal estruturação começa a ser esgarçada a partir dos anos 1960, com a emergência de maior autonomia financeira feminina. "Historicamente, o consumo feminino foi organizado em torno das necessidades do marido e dos filhos. Frequentemente, a mulher consumia em nome de terceiros em detrimento de si mesma", porém, "uma vez que elas se tornaram economicamente independentes, as mulheres puderam entrar no mundo do consumo para satisfazer as suas próprias necessidades e desejos" (Stillerman, 2015: 113).

A coluna "Escolhendo e Comprando com Helena Brazil" emerge justamente nesse período de transição de imaginários de consumos femininos, em que a ideia de compras para a família convive com a ideia de um consumo mais voltado para si, de forma que tal tensionamento está latente em seus textos. Helena Brazil era uma figura pública conhecida mesmo antes da publicação de suas colunas como presidente de honra da Liga das Donas de Casa (LDDC). Além de seu trabalho no Diário de Notícias, ela publicou alguns livros e folhetos sobre educação financeira para mulheres e costumava promover cursos e palestras em clubes e associações sobre a temática do bem consumir.

Em sua coluna no Diário de Notícias, os textos também eram voltados exclusivamente para mulheres - de forma que todos os termos vocativos relacionados ao leitor eram usados no feminino. Para retratar a temática do consumo, a coluna tratava as práticas de compra como formas eficazes de resolver problemas do cotidiano das mulheres (e, portanto, estava embebida no imaginário dos comportamentos esperados) e utilizava, como principal estratégia discursiva e argumento de autoridade, o testemunho pessoal combinado com um apelo direto às consumidoras.

O eixo central da coluna estruturava-se em torno do aconselhamento às leitoras sobre quais eram as melhores lojas e ofertas disponíveis, em uma mimetização da linguagem dos anúncios comerciais da época. Assim, era possível encontrar trechos como: "Uma casa onde você pode escolher os mais lindos aparelhos de iluminação é Dominiei, R. Figueiredo Magalhães, 285" (DN, 29/05/1962); "A última palavra em aparelhos de surdez é a maravilha austríaca 'Viennatone'. No Rio, você encontra à venda na Avenida Rio Branco, 20 - 19o andar. Sinceramente, eu não sei o preço... mas quanto vale o milagre de ouvir novamente?” (DN, 03/07/1962).

Grande parte de suas colunas eram também voltadas à denúncia de estabelecimentos e marcas que prestassem um mau serviço às consumidoras, em um exercício que se aproximava ao gênero do jornalismo de utilidade social. Muitas vezes, inclusive, não apenas o nome da loja em questão era exposto, como a própria Helena Brazil escrevia que iria intervir diretamente no caso, entrando em contato com os responsáveis. Tal abordagem pode ser encontrada em trechos como: "É verdadeiramente incrível a oscilação de preços das lojas da Avenida Copacabana e Barata Ribeiro. A dona de casa 
que não procura informar-se é explorada sem cerimônia" (DN, 06/11/1962) ou "Leitora E.R.: Estou escrevendo para os fabricantes, dando ciência de suas reclamações. Em casos idênticos, a Hoover e a GE tomaram providências. Aguarde” (DN, 02/04/1963).

Algumas vezes, o espaço da coluna era utilizado, inclusive, para a crítica política, embora isso fosse pouco usual. Isso pode ser observado em trechos como: "Se a intenção era prejudicar as donas de casa, o governador conseguiu em cheio determinando o fechamento das padarias aos domingos. A LDDC é contra e eu apoio a LDDC”. (DN, 29/05/1962). Frequentemente, em suas colunas, a autora também pedia a suas leitoras doações a entidades de caridade específicas.

Além disso, suas colunas eram permeadas por aconselhamentos financeiros. $\mathrm{Na}$ edição de 06/08/1963, ela expunha, entre outras recomendações:

Devo lembrar sempre a minhas leitoras, a você, que a principal função dessa coluna é difundir as regras básicas da arte de comprar. Hoje faço uma recapitulação de tudo o que tenho dito. E só espero que você aplique esses ensinamentos na sua vida diária, pois assim aproveitará melhor o seu dinheiro, o dinheiro da sua família, podendo desfrutar uma vida mais equilibrada e mais feliz. $1^{\circ}$ Analise bem o motivo da compra antes de a efetuar; (...) $7^{\circ}$ Tenha cuidado: nem sempre o mais anunciado é o melhor (...) $10^{\circ}$ Compre no melhor estabelecimento mais próximo da sua casa; $11^{\circ}$ Exija do comerciante um estabelecimento amplo, claro, higiênico, bem decorado; (...) $13^{\circ}$ Guarde seu dinheiro em bancos. Habitue-se a pagar em cheque (...) $18^{\circ}$ Defenda-se do consumismo. Não transforme seu lar num depósito de compras. $19^{\circ} \mathrm{O}$ testemunho da estrela, da cantora, da Dama, do técnico, da moça da propaganda vale menos do que sua experiência. (...) $20^{\circ}$ Boatos alarmistas são maus conselheiros de compras; $21^{\circ}$ Diga 'vou pensar' antes de fechar um negócio importante; $22^{\circ}$ Não seja uma eterna concorrente de suas amigas e vizinhas (DN, 06/08/1963).

Não se tratava, portanto, de uma coluna voltada exclusivamente aos anúncios comerciais (embora eles compusessem uma parte significativa de sua estruturação), mas sim, de um texto híbrido que misturava os elementos de publicidade à linguagem jornalística da época. Além disso, trata-se de um gênero bastante específico do discurso, a coluna de aconselhamento, que aliava à legitimação da voz do especialista como voz de autoridade a partir da construção de um lugar de expertise sobre um determinado assunto - bem como marcado por estratégias textuais voltadas à construção simbólica dessa expertise.

É necessário considerar que o hibridismo de suas colunas e o enquadramento dado aos temas está em consonância com o projeto editorial mais amplo do Diário de Notícias, de matriz conservadora. Fundado em 12/07/1930 por Orlando Ribeiro Dantas, Nóbrega da Cunha e Alberto Figueiredo Pimentel Segundo, três jornalistas 
egressos dos Diários Associados, o jornal tinha um viés conservador tanto do ponto de vista social quanto econômico. O filho de Orlando Dantas, João Ribeiro Dantas, exprime a maneira como o público-alvo do jornal era delineado em relação aos seus concorrentes nos seguintes termos: "sua linha era eminentemente voltada para a classe média: servidores públicos, civis e militares, juízes. O Correio da Manhã, seu concorrente, era um jornal de elite. O Diário era um jornal patriota, interessado nos problemas nacionais" (apud Cadernos da Comunicação, 2006: 16). Em depoimento, Fernando Segismundo comenta que "o Diário de Noticias foi fundado para ser um jornal dirigido à classe média, classe média alta - isto é, uma classe média de orientação udenista, bem à direita". Assim, "a linha doutrinária do jornal era dada por pessoas como o deputado Otávio Mangabeira, da velha UDN, que fazia a cabeça dos Dantas, da mesma forma que o deputado, também da UDN, Adauto Lúcio Cardoso, Osório Borba, (...) o brigadeiro Eduardo Gomes e (...) Eduardo do Prado Kelly" (apud Cadernos da Comunicação, 2006: 30). Para João Dantas (apud Cadernos da Comunicação, 2006: 50), o período áureo, em termos financeiros, do Diário de Notícias aconteceu entre 1956 a 1965, com o aumento de editorias, de posses e de receitas. Em 1964, o jornal apoia o golpe militar, mantendo a sua linha editorial conservadora, embora isso não tenha se materializado em um maior apoio publicitário por parte das empresas estatais para a publicação, o que marca o início de sua queda em termos financeiros.

A educação era uma das temáticas prioritárias de seu projeto editorial, reiterada em diversas seções, de forma que o jornal adotava uma postura didática em relação a seus leitores, especialmente nos assuntos voltados à cultura em geral. $\mathrm{O}$ jornal também foi um dos primeiros a criar um caderno especialmente para assuntos considerados femininos.

"Escolhendo e Comprando com Helena Brazil" fazia parte dessa estratégia editorial mais ampla, baseada em um tom didático e uma postura conservadora, preocupada com a educação da mulher de classe média. Uma vez expostas as características gerais da seção, iremos, na sequência, analisar as estratégias discursivas utilizadas por ela, especialmente no que concerne às estratégias de construção de um lugar de autoridade no discurso, conforme exposto inicialmente. Como adiantado, a construção do direito ao lugar de fala nos textos de Helena Brazil está engendrada a uma questão de gênero, conforme iremos discutir. Os textos foram consultados junto à hemeroteca digital da Biblioteca Nacional. Para a análise, eles serão decompostos tanto no nível formal - em seus aspectos narrativos e retóricos - quanto no plano do conteúdo.

\section{A mulher como corpo consumidor e as estruturações discursivas de um lugar de autoridade}

A partir de uma leitora extensiva dos textos de Helena Brazil, é possível mapear algumas estratégias discursivas de construção de um lugar de autoridade que se 
repetem em todas as suas colunas. No plano formal, a saber, elas são: a remissão às máximas, o apelo ao testemunho e a remissão à leitora como actante narrativo. No plano do conteúdo, elas estão relacionadas a um ideal de gênero e a um imaginário de consumo, como será esmiuçado a seguir. Ao todo, foram analisados trinta textos, publicados entre 1962 e 1963.

\section{I. As máximas e a marcação de um lugar de conflito}

Os aconselhamentos de "Escolhendo e Comprando com Helena Brazil" usavam um expediente narrativo em comum: a remissão a um suposto problema cotidiano da leitora e sua resolução a partir do ato de consumo. É nesse sentido que encontramos trechos como "Muitos maridos gostam de sair à noite, sozinhos e uma das razões é não terem nada para fazer que os prenda em casa. Você também tem esse problema? Então aqui vai um conselho de amiga: ofereça-lhe um trem elétrico da Train Shop. Avenida Rio Branco, 156" (DN, 28/08/1962) ou "Para uma dona de casa, é sempre bom conhecer alguns detalhes de decoração. E se você está interessada em fazer um curso, recomendo-lhe procurar a Décor" (DN, 14/08/1962) ou, ainda, "Seu marido quer montar um pequeno escritório em casa? Diga-lhe para ver os lindos móveis de Kastrup, Avenida Fraklin Roosevelt, 146-B" (DN, 27/11/1962).

Os problemas evocados tomavam a forma de uma máxima, a partir do remetimento a um suposto princípio evidente, reconhecido e compartilhado por seus interlocutores, o que se materializa a partir do uso de expressões como "é sempre bom" ou "muitos maridos". Há, aqui, portanto, a construção de um campo comum entre o enunciador e o enunciatário, uma vez que o texto se alicerça a partir de um operador argumentativo que pressupõe a existência de "uma comunidade linguística que admite partilhar" certos entendimentos comuns sobre o mundo, "uma comunidade à qual pertençam pelo menos aquele que realiza a demarche argumentativa e aquela a quem ela é proposta”. (Ducrot, 1987: 24). A construção desse campo comum carrega uma série de estereótipos não apenas sobre o gênero feminino como também dos demais membros da família, efetuando a partilha entre os comportamentos considerados adequados e os pouco usuais. Ele parte, também, de um determinado imaginário sobre o consumo, que coloca a mulher como um agente especializado de compras para a casa, mesmo quando é o marido ou os filhos que irão usufruir dos bens. É a partir da universalidade e generalidade das proposições que remetem à vida cotidiana da leitora que se constroem os gatilhos de um lugar de autoridade no discurso de aconselhamento.

Mais do que isso, é justamente a remissão a esse campo comum de entendimento que irá marcar o lugar do conflito na narrativa urdida por Helena Brazil: arma-se um problema, legitimado pelo senso comum, que deverá ser resolvido a partir de um ato de consumo. O valor de máxima e de senso comum atribuído ao conflito é transferido 
e delegado, na sequência, à sua solução, apontada por Helena Brazil como evidente. Essa solução do conflito está sempre posta em um ato de consumo, de forma que as práticas de consumo se tornam adjuvantes de uma narrativa que tem como heroína a própria leitora. Como facilitador do processo, está a própria Helena Brazil que, com sua expertise, ocupa o papel de destinador da narrativa, se pensarmos no esquema actancial proposto por Greimas (1966). O lugar ocupado por Helena Brazil, como narradora do relato é, portanto, um lugar de autoridade já no nível narrativo.

Se pensarmos no nível retórico, é possível dizer que a coluna de Helena Brazil combina, assim, estratégias discursivas que se alicerçam em uma estratégia tríplice de construção de um lugar de autoridade: "como uma máxima verdadeira naquilo que afirma, conveniente naquilo que prescreve, útil em função das circunstâncias em que nos encontremos". (Foucault, 1992: 140). Ou, em outros termos, a sua estratégia de legitimidade estrutura-se no tipo de escrita que Foucault (1992: 140) identifica como "uma arte da verdade contrastiva", ou seja, "uma maneira refletida de combinar a autoridade tradicional da coisa já dita com a singularidade da verdade que nela se afirma e a particularidade das circunstâncias que determinam o seu uso".

Retoricamente, a construção do lugar de autoridade na coluna "Escolhendo e Comprando com Helena Brazil", portanto, tem como um dos seus principais gatilhos a articulação de uma estratégia argumentativa dupla: a remissão à verdade de uma máxima (que, em termos narrativos, estrutura o conflito do relato) e a alusão ao valor circunstancial de uso de um ato de consumo (que resolve o conflito da narrativa). Narrativamente, está no posicionamento do narrador como destinador no relato, o que já em si a ocupação de um lugar de autoridade e legitimidade.

Ora, a partir da decomposição dessas estratégias de construção do discurso do especialista, é possível perceber que, ao se embasar no remetimento ao senso comum articulado como máxima como sua base de sustentação, o cerne da estratégia discursiva passa necessariamente por uma questão de gênero no nível do conteúdo: toda a argumentação está embasada na partilha entre os comportamentos de consumo esperados para homens e para mulheres e, consequentemente, no consentimento do auditório sobre os termos dessa partilha. Sem esse remetimento a esse suposto campo comum de entendimento, toda a estratégia de legitimação do discurso se desconstrói.

Tal estratégia de construção discursiva do expert, contudo, se coaduna a uma outra, ainda mais importante do que as descritas até esse momento: o apelo ao testemunho do enunciador, conforme esmiuçaremos a seguir.

\subsection{O apelo ao testemunho}

A principal característica discursiva da coluna de Helena Brazil é o uso de seu próprio testemunho como articulador do relato e fiador da veracidade da narrativa. É através de sua própria experiência vivida que a narradora opera a demonstração de 
sua expertise e a confirmação de sua legitimidade como consultora de compras. Nesse sentido, podemos encontrar, por exemplo, as seguintes estruturações: "Diversas famílias minhas conhecidas estão insistindo comigo para ir passar um fim de semana em Teresópolis. E inclusive chamam minha atenção para o Ed. Planalto que está sendo incorporado na Várzea, com apartamentos de 1 e 2 quartos no centro do maravilhoso jardim com piscina. Quem vende é a Carleg, tel 42-3557, aqui no Rio. Irei lá na primeira oportunidade" (DN, 03/07/1962), "Só seleciono as melhores lojas, só indico as melhores ofertas. Se você tem alguma queixa ou reclamação, escreva-me sem receio" (DN, 03/07/1962) ou "Mesmo só para ver, faça uma visita a O Balão Vermelho, em frente ao Imperador. E diga a Dona Maria da Graça que você é minha recomendada" (DN, 29/05/1962). A remissão à presença física de Helena Brazil nas lojas anunciadas e sua experiência pessoal com os produtos apresentados são citados de forma sistemática, de forma que é o testemunho pessoal da narradora que confere legitimidade ao relato.

A estratégia argumentativa aqui proposta, portanto, está na remissão ao testemunho e no fato de que "a narrativa é factualizada pela presença de seu narrador em relação ao evento reportado”. (Dulong, 1998: 15). Isso pode ser interpretado no sentido de que é o próprio corpo da testemunha que funciona como uma espécie de presentificação do acontecimento em torno do qual ela testemunha, funcionando como garantia imaginária da verdade do relato. É sobre essa base que está a pressuposta legitimidade de especialista de Helena Brazil - como alguém capaz de testemunhar sobre as melhores compras porque ela própria as experimentou.

$\mathrm{Na}$ acepção de Agamben, o que explica essa força de uma suposta verdade presente no testemunho é a sua característica como performativo que ele assume na linguagem. "O verbo performativo constrói-se necessariamente com um dictum que, considerado em si, tem natureza puramente denotativa, e sem o qual ele continuaria vazio ou ineficaz ('eu juro' não tem valor se não for seguido - ou precedido - por um dictum que o preenche)". Apesar disso, esse dictum é revogado no mesmo instante em que ele é precedido por esse "eu juro": a sua força denotativa perde importância e proeminência, na medida em que é a força performativa da promessa que adquire o primeiro plano na sentença. E "assim, o performativo substituiu a relação denotativa entre palavra e coisa por uma relação autorreferencial que, excluindo a primeira, põe a si mesma como o fato decisivo". (Agamben, 2011: 66). Na suspensão da relação denotativa, é o próprio modelo de verdade de um enunciado que é rearticulado a partir do uso do performativo: "o modelo de verdade não é, nesse caso, o da adequação entre as palavras e as coisas, mas sim aquele do performativo, no qual a palavra realiza inevitavelmente o seu significado". A implicação disso está no fato de que, no testemunho, é estabelecida uma distinção entre o próprio juramento e o seu conteúdo semântico. Nesses termos, a relação que ele estabelece com o verdadeiro está no seu próprio aspecto formal, independentemente do conteúdo que serve de objeto ao testemunho. Se o testemunho é um ato verbal que realiza uma garantia

62 ALCEU - v. 18 - n.36 - p. 54 a 69 - jan-jun./2018 
independentemente de o fato enunciado acontecer ou não, é porque a sua força performativa reside na forma, reside em seu significante, independentemente da asserção que o acompanha. Nesses termos, há uma promessa de verdade imaginária inserida no testemunho que se instala independentemente do assunto relatado.

A principal estratégia de construção de um lugar do especialista na coluna de Helena Brazil, portanto, se vale justamente desse expediente retórico: o calçamento da veracidade do relato na corporalidade do narrador e na força performativa de um testemunho a partir de uma escrita sobre si. É porque ela pode dar o seu testemunho que ela pode ser considerada uma expert, independentemente do conteúdo que suporta esse testemunho mesmo. $\mathrm{O}$ voto de confiança do narrador é pedido aos seus leitores a partir de um suposto "eu estive lá" e, portanto, "acreditem em mim". (Ricoeur, 2007).

A escrita de si, para Foucault (1992: 129), é nada mais do que "um operador da transformação da verdade em ethos". Por esses termos, ele refere-se ao fato de que o testemunho registrado emerge no mesmo movimento a partir do qual a escrita passa a exercer um papel importante para o estabelecimento das regras do bem viver e para "a elaboração dos discursos recebidos e reconhecidos como verdadeiros em princípios racionais de ação", como um elemento importante do treino e do cuidado de si.

$\mathrm{Na}$ coluna de Helena Brazil, é justamente o calçamento no testemunho e nessa escrita de si que funciona como o fiador de veracidade do relato, de forma que ela se torna o agente especializado para testemunhar as melhores ofertas. Essa posição de autoridade da testemunha, contudo, também passa, nesses textos, por uma questão de gênero: se no nível formal, é o próprio testemunho que pede um voto de autenticidade para o relato, no nível do conteúdo, tal pedido é sustentado por uma posição de gênero. O testemunho de Helena Brazil é acreditado e sustentado, ganhando em autenticidade, justamente porque o narrador é uma mulher - que, no imaginário das práticas de consumo da época se coadunava como agente familiar especializado da manutenção das compras da casa e para a família.

No plano do conteúdo, ainda, tal acreditação ao testemunho de Helena Brazil é reforçado pelas constantes remissões que ela faz à Liga das Donas de Casa. A sua condição de presidente de honra da instituição é constantemente reiterada o que confere legitimidade ao discurso pela vinculação institucional do orador (como uma figura de autoridade) e, principalmente, pelo seu posicionamento social (uma dona de casa) uma figura autorizada imaginariamente, portanto, para falar do consumo da família.

A questão do gênero é tão importante que, algumas vezes, isso emergia de forma mais incisiva nos textos da coluna. Em um deles, por exemplo, ao responder a uma carta de um dos leitores, Brazil responde a um homem e a conselheira registra o seu espanto na própria resposta: "Leitor desconhecido de Vila Isabel: abro uma exceção ao seu caso. Ligue para o Sr. Cícero, tel: 52-0140. Ele pode ajudá-lo" (DN, 28/08/1962). A exceção, nesse caso, referia-se ao fato de se tratar de um leitor 
e não de uma leitora, o que confirma a importância do gênero para a estruturação discursiva de um lugar de autoridade no relato.

Tal estratégia discursiva calçada no testemunho de Brazil (como actante narrativo), contudo, se combina a uma outra, igualmente importante para a construção do lugar de autoridade do relato: em "Escolhendo e Comprando com Helena Brazil", o enunciador não é o único fiador testemunhal do relato. Ela divide, narrativamente, esse lugar com a sua própria leitora. Em todas as colunas de Helena Brazil, as leitoras operavam como um actante narrativo bastante importante para a construção do lugar de autoridade do relato. Isso se dava a partir de duas estratégias discursivas distintas. A primeira delas consistia em transformar as leitoras em correspondentes de Helena Brazil, de forma que elas poderiam enviar cartas a ela, contando sobre as melhores ofertas e promoções encontradas em sua vida cotidiana. A segunda estratégia consistia em incentivar que as leitoras mandassem cartas para ela - cartas que eram respondidas na própria coluna. Cada uma dessas estratégias engendravam lugares de autoridade distintos, conforme iremos expor na sequência.

\subsection{A triangulação no apelo às leitoras}

\subsection{As correspondes de Helena Brazil e a terceirização do testemunho}

A partir de meados da década de 1940, os textos jornalísticos passam a adotar uma estratégia discursiva que, até então, era pouco utilizada nas reportagens em geral: aquela a que Mesnard (2005: 175) chama de estética da profusão do ponto de vista e que consiste na inserção, no texto, da fala de testemunhantes do evento retratado que não o próprio repórter. Se, no período anterior, as reportagens se fiavam quase exclusivamente no testemunho do repórter enquanto um agente especializado para contar os fatos, a partir desse período há o desdobramento do ponto de vista em direção a outros testemunhantes e é possível observar uma maior preocupação jornalística com a perspectiva das outras testemunhas (Casadei, 2013).

Tal característica narrativa também pode ser observada na coluna de Helena Brazil: o discurso e o testemunho do expert não se sustentam sozinhos e eles são suportados por um apelo em direção às leitoras para que elas também contribuam com a construção desse lugar de autoridade. Em "Escolhendo e Comprando com Helena Brazil", as leitoras frequentemente eram convocadas para atuarem como correspondentes da consultora de compras, indicando ofertas e estabelecimentos interessantes para as demais consumidoras, o que pode ser exemplificado em trechos como: "Brevemente você poderá ser correspondente de Helena Brazil. Fique atenta" (DN, 29/05/1962), "Méier - a visita da minha assistente às lojas Méier teve que ser alterada. Mas ela irá essa semana" (DN, 29/05/1962), "Você já é minha correspondente? Então você vai ter grandes surpresas!" (DN, 03/07/1962), "As críticas, queixas,

64 ALCEU - v. 18 - n.36 - p. 54 a 69 - jan-jun./2018 
reclamações e sugestões das minhas leitoras são sempre bem recebidas. Estamos a serviço das donas de casa. Escrevam" (DN, 14/08/1962).

Helena Brazil, nesse caso, funcionava como uma curadora das cartas recebidas, filtrando as informações que seriam publicadas na coluna. Narrativamente, contudo, há um mecanismo de construção de um lugar de autoridade em que a confiabilidade do relato se desloca da corporalidade (narrativa) de Helena Brazil e passa a ser dividida com outras testemunhas que também passam a servir como lastro de veracidade em torno do narrado. Mais do que isso, trata-se, aqui, de um mecanismo em que há a construção da imagem do outro (a leitora) como mimetização da imagem de si (o actante Helena Brazil). A valorização da leitora como também uma especialista em compras se sustenta, no plano do conteúdo, pela partilha dada a homens e mulheres no que diz respeito às suas práticas de consumo: assim como Helena Brazil, elas também possuem imaginariamente uma experiência prática, adquirida supostamente no curso da vida vivida como donas de casa, sobre as melhores ações de consumo para a sua família. Há um mecanismo de valorização da leitora (como personagem da narrativa) que passa a carregar, ela mesma, uma função de verdade no relato (sustentada pelo plano formal do testemunho). Há, aqui, portanto, a construção, no plano formal, de uma mimetização da autoridade de Helena Brazil na própria leitora, que é valorizada enquanto actante narrativo do relato - valorização essa que se sustenta, no plano do conteúdo, pelo imaginário de que toda mulher seria uma expert em consumo para casa.

A projeção da leitora na narrativa, contudo, tem como efeito de sentido um ganho de legitimidade para a própria coluna de Helena Brazil, posta como um lugar de autoridade pela multiplicação dos testemunhos. A mimetização do comportamento de Brazil em suas leitoras constrói um espaço para as identificações cuja implicação é a transferência do valor que cada leitora dá a si própria e a seus pares como especialistas do consumo para a coluna de Helena Brazil.

A reafirmação da autoridade de Helena Brazil a partir da inserção da leitora como actante narrativo se dá ainda em um outro aspecto, que será exposto a seguir: a saber, a resposta às cartas das leitoras.

\subsubsection{As respostas às leitoras e a confirmação da autoridade}

Um espaço considerável da coluna de Helena Brazil era destinado a responder dúvidas de consumo enviadas pelas leitoras por cartas. Tais respostas eram dadas nos seguintes termos: "Leitora A.R.: Obrigada!", "Leitora J.S.A.: Aguarde carta", "Leitora S. L.: Infelizmente não poderei comparecer", "Leitora M.A.P.: Era eu, sim" (DN, 14/08/1962), "Leitora R.S.: Muito obrigada pelo seu convite de casamento" (DN, 02/04/1963). Curiosamente, as cartas das leitoras eram respondidas na própria coluna sem que, no entanto, elas fossem transcritas, de forma que ao leitor era permitido ler a resposta de Helena Brazil, mas não a pergunta feita pela leitora. 
No início, as respostas eram bastante pontuais e, com o tempo, aumentam o tom de intimidade e, principalmente, o ímpeto na resolução dos problemas apresentados pelas leitoras, aproximando-se do jornalismo de utilidade social. São exemplos disso os trechos: "Leitora Z.H.: Infelizmente não posso concordar com você. Já admitiu a hipótese de fazer um mau negócio, gastando dinheiro que custou a ganhar?" (DN, 06/11/1962), "Leitora M.M.C.L.: O seu problema não é para mim, conselheira de compras. É muito mais para a polícia ou para um bom advogado" (DN, 27/11/1962), "Leitora L.S.V.: Vou escrever para as autoridades competentes" (DN, 27/11/1962).

Um dos sintomas da importância da participação da leitora para a estruturação discursiva dos textos publicados na coluna pode ser encontrado nos apelos frequentes que Brazil fazia para que as leitoras continuassem a escrever para ela: "Minha correspondência com as leitoras da zona norte está atrasada. Desculpem-me... e escrevam!" (DN, 06/11/1962), "Quando tiver alguma dúvida sobre alguma compra a fazer, pode perguntar a vontade que sempre procurarei esclarecer, orientar, alertar, servir" (DN, 14/08/1962). Isso pode ser exemplificado, ainda, no seguinte trecho, que misturava a estratégia do testemunho de um terceiro ao apelo comercial: "Estou muito contente: uma leitora me escreveu carta, sensibilizada e agradecida, dando-me a notícia de ter restituído a audição de sua velha mãezinha com um aparelho recomendado por mim nessa coluna. E pede-me que transmita a todas as outras leitoras seu contentamento pela maneira gentil com que foi tratada no Centro Auditivo Telex, Av. Rio Branco, 138” (DN, 27/11/1962).

O recurso às cartas, para Foucault (1992: 152) "é simultaneamente um olhar que se volve para o destinatário (por meio da missiva que recebe, ele sente-se olhado) e uma maneira de o remetente se oferecer ao seu olhar pelo que de si mesmo the diz", de forma que "de certo modo, a carta proporciona um face-a-face". Em outros termos, o recurso às cartas engendra um ponto importante para a construção de um lugar de autoridade e legitimidade do expert no relato porque ele remete a uma encenação de uma abertura ao outro. Ela implica a valorização de um lugar para a leitora na narrativa, em um reforço do mecanismo de construção de um espaço de identificação possível.

A questão, contudo, é que essa suposta abertura ao outro engendra uma construção mais apurada do ethos do enunciador, voltando-se, portanto, a um lugar de autoridade do expert no discurso. Ao passo que as cartas das consumidoras não eram transcritas no relato, cabendo aos leitores uma decifração da pergunta efetuada, é possível aventar que a função das cartas era muito mais a atestação da capacidade de resposta de Helena Brazil, que reafirmava o seu suposto saber sobre, do que a resolução do problema propriamente dito. Trata-se sim, de um recurso de reafirmação da autoridade do expert em seu trabalho de consultoria, a partir do engendramento de uma resposta de tom professoral - de forma que a própria capacidade de resposta serve como lastro imaginário da legitimidade do respondente. 
No plano do conteúdo, é possível dizer que frequentemente as repostas de Helena Brazil seguiam uma tomada de ação, de forma que ela se colocava não apenas como uma consultora de compras, mas também como uma ajudante da leitora na resolução de seus problemas. Tal postura se aproxima de uma intersecção entre as características da coluna de aconselhamento de compras com as do jornalismo de utilidade social e de resolução de problemas. O conceito de jornalismo de utilidade social "identifica a ação jornalística como tendente a servir aos interesses concretos dos cidadãos e a responder às preocupações dos leitores ou da audiência referentes a emprego, habitação, educação, segurança, qualidade de vida" e, inclusive, consumo. "A imprensa assumiria aí o papel de mediadora e de interventora na sociedade", de forma que "a utilidade pública impõe ao jornalista uma maior aproximação com o público, uma participação intensa na vida da comunidade, um maior engajamento" (Abreu, 2003: 30). No Brasil, desde a década de 1950, alguns jornais já adotavam tal estilo de jornalismo, em espaços que abarcavam as queixas de seus leitores através das seções de serviços e que colocavam o jornalista como uma espécie de prestador de serviços ao público. A coluna de aconselhamentos de Helena Brazil, entre outras funções, também abarcava essa linguagem do jornalismo de utilidade social.

Tal expediente engendra também um lugar de autoridade e legitimidade no relato na medida em que atesta não apenas a capacidade do narrador de responder a um questionamento ou indicar os melhores negócios a partir da esfera testemunhal, mas, principalmente, anuncia sua capacidade de agir no mundo, interferindo no vivido e operando como uma espécie de paladino de boas práticas. O discurso de autoridade se desloca do testemunho para a ação, cuja possibilidade serve de lastro para a veracidade do narrado.

\section{Considerações finais}

A construção de um lugar de legitimidade para o discurso do expert pode se dar a partir de inúmeras estratégias discursivas tanto no plano formal da narrativa e da retórica quanto no plano do conteúdo. As tramas discursivas de edificação de um lugar de legitimidade de fala urdidas na coluna "Escolhendo e Comprando com Helena Brazil" deixam entrever uma triangulação específica e historicamente demarcada entre o lugar do expert-narrador, o lugar do leitor e o imaginário sobre o consumo.

No que diz respeito ao primeiro termo, referente ao enunciador do discurso, conforme esmiuçado ao longo do artigo, a remissão aos problemas diários da leitora colocados sob a forma de máximas no plano retórico assumem, no plano narrativo, a condição de posicionar o actante Helena Brazil como um destinador do relato, ou seja, uma figura de autoridade que proporciona a ação ajudando a resolver o conflito através de atos de consumo. Além disso, trata-se de um actante autorizado pela instância testemunhal (no plano da retórica) que é ainda mais acreditada por seu posicionamento institucional como personagem pertencente à LDDC. Além disso, 
o lugar de autoridade do narrador também se dá a partir de estratégias discursivas que efetuam um espelhamento entre o testemunho do especialista e a construção da leitora como personagem da narrativa, com o engendramento de uma suposta relação mimética entre a autoridade suposta do próprio narrador e do seu público, de forma que ambos são projetados como experts em consumo. Tal expediente se sustenta, ainda, no plano do conteúdo, pela mediação do lugar imaginário do gênero e do consumo feminino, que posicionavam a mulher em um lugar de fala validado para lidar com as compras triviais da família e da casa.

A autoridade e a legitimidade dos discursos referenciais, tal como afirma White (2008), não dependem apenas de processos externos às narrativas urdidas, mas são determinadas, sobretudo, por modelos retóricos e de narração específicos que dependem, em última análise, da natureza das preconcepções poéticas e de estilo. São determinadas, ainda, pelos imaginários que atravessam os grupos sociais e os supostos papéis sociais que são destinados a seus membros em intersecção com suas práticas cotidianas. Assim, os discursos de autoridade não são apenas produções simbólicas genéricas, mas sim, emergências de um certo tipo de relacionamento que mantemos com o imaginário presente mediado por um tipo distintivo de discurso escrito. O mapeamento das estratégias de construção do lugar de autoridade utilizadas pela coluna "Escolhendo e Comprando com Helena Brazil" nos remete ao fato de que a estruturação discursiva do consumo nas práticas midiáticas também segue padrões de estilo e preconcepções poéticas específicas e historicamente marcadas, permeadas pelos imaginários e pelas valorações sociais sobre o que significa consumir para cada ator e grupo social, em um momento histórico específico.

Eliza Bachega Casadei

Professora da Escola Superior de Propaganda e Marketing (ESPM-SP) Doutora em Ciências da Comunicação (USP)

Recebido em dezembro de 2016.

Aprovado em dezembro de 2017.

\section{Referências}

ABREU, Alzira Alves de. Jornalismo cidadão. Estudos Históricos, Rio de Janeiro, n. 31, p. 23-40, 2003.

AGAMBEN, Giorgio. O Sacramento da Linguagem: arqueologia do juramento. Belo Horizonte: Editora UFMG, 2011.

CASADEI, Eliza Bachega. Os códigos padrões de narração e a reportagem: por uma história da narrativa do jornalismo de revista no século XX. Tese de doutorado apresentada à Escola de Comunicações e Artes da Universidade de São Paulo. São Paulo: ECA-USP, 2013.

CADERNOS DE COMUNICAÇÃO. Diário de Notícias. Rio de Janeiro: Prefeitura da Cidade do Rio de Janeiro, 2006.

68 ALCEU - v. 18 - n. 36 - p. 54 a 69 - jan-jun./2018 
CERTEAU, Michel de. A Escrita da História. Rio de Janeiro: Forense Universitária, 2008.

DUCROT, Oswald. O dizer e o dito. São Paulo: Pontes: 1987.

DULONG, Renaud. Le Témoin Oculaire: Les conditions sociales de l' attestation personnelle. Paris: École des Hautes Études en Sciences Sociales, 1998.

FOUCAULT, Michel. A escrita de si. In:___. O que é um autor? Lisboa: Passagens, 1992. GREIMAS, Julien Algirdas. Semântica Estrutural. São Paulo: Cultrix, 1966.

MAINGUENEAU, Dominique. "Analysis of an academic genre". Discourse Studies, v. 4, n. 3, Junho de 2002, p. 319-341.

MESNARD, Philippe. À la articulation des points du vue. In: DORNIER, Carole; DULONG, Renaud. Esthétique du Temoignage. Paris: Éditions de la Maison des sciences de l'homme, 2005.

RICOEUR, Paul. A Memória, a História, o Esquecimento. Campinas: Editora da Unicamp, 2007. STILLERMAN, Joel. The Sociology of Consumption: a global approach. Cambridge: Polity Press, 2015.

WHITE, Hayden. Meta-História: a imaginação histórica do século XIX. São Paulo: Edusp, 2008.

\title{
Resumo
}

A partir do pressuposto de que as formas de escrita que comportam os discursos dos especialistas mudam ao longo do tempo, de maneira que as estratégias utilizadas pelos diferentes grupos de experts para manter a sua credibilidade no discurso são historicamente marcadas, o artigo tem como objetivo analisar a construção dos processos de legitimidade do discurso da coluna "Escolhendo e Comprando com Helena Brazil", publicada pelo Diário de Notícias, de 1962 a 1963. Para isso, iremos decompor os textos no nível formal (planos narrativo e retórico) e no plano do conteúdo, para entendermos as estratégias de construção do lugar de autoridade no relato. No plano do conteúdo, a conquista de um lugar de fala remete à questão da mediação do lugar imaginário do gênero e do consumo feminino. No plano formal, diz respeito à remissão às máximas, o apelo ao testemunho e a remissão à leitora como actante narrativo.

\section{Palavras-chave}

Jornalismo. Consumo. Autoridade. Legitimidade. Discurso.

\begin{abstract}
From the assumption that the forms of writing that behave the speeches of experts change over time, so that the strategies used by different groups of experts to maintain its credibility in the speech are historically marked, this article aims to analyze the construction of discourse legitimacy processes of the column "Escolhendo e Comprando com Helena Brazil" ("Choosing and Buying with Helena Brazil"), published by Diário de Notícias, from 1962 to 1963. For this, we will decompose its texts in the formal level (narrative and rhetorical plans) and in the content level, to understand the construction of authority strategies in the reporting. In the plan of content, it concerns to the mediation of imaginary places of gender and women's consumption. Formally, it concerns to the reference to common sense, the appeal to the testimony and the remission to the reader as a narrative actant.
\end{abstract}

\section{Keywords}

Journalism. Consumption. Authority. Legitimacy. Speech. 